\title{
Development of Latent Fingerprints on Non-Porous Surface with Fluorescent Dye Based Small Particle Reagent
}

\author{
Akshita Verma"1, Nisha², Dr. Tulika Banerjee ${ }^{3}$, Dr. G. S. Sodhi ${ }^{4}$ \\ ${ }^{*}$ Lecturer, Department of Forensic Science, School of Science-II, Jain (Deemed-to-be) University, JC Road \\ Campus, Bengaluru, Karnataka, India \\ ${ }^{2}$ Scientific Assistant, Crime Scene Management Division, Forensic Science Laboratory, Govt. of NCT of Delhi, \\ Delhi India \\ ${ }^{3}$ Assistant Professor, Forensic Science Unit, SGTB Khalsa College, University of Delhi, Delhi, India \\ ${ }^{4}$ Associate Professor and Course Coordinator, Department of Chemistry, Forensic Science Unit, SGTB Khalsa \\ College, University of Delhi, Delhi, India
}

\section{ABSTRACT}

Article Info

Volume 8, Issue 3

Page Number : 443-447

\section{Publication Issue}

May-June-2021

\section{Article History}

Accepted : 25 May 2021

Published : 31 May 2021
Fingerprints are a useful source of evidence in establishing the identity of the person and hold large importance in crime scene investigations. A diverse range of physical and chemical methods are available for the development of latent fingerprints, but limited work is done on detection of prints from wet non-porous surfaces. The study aimed at developing a novel method for identification of latent fingerprints from such a type of surface. Small Particle Reagent was prepared using non-toxic chemicals and was proven to be effective in detecting latent fingerprints on Aluminum Foil. Fluorescent component, Basic Yellow-40 dye was used in the formulation. The Shelf life of the SPR solution was also considered an important factor in the study and was found to be 25 days.

Keywords : Fingerprint, Small Particle Reagent, Non-porous surface, Shelf Life, Forensic Science

\section{INTRODUCTION}

Fingerprint examination is considered as one of the most important examinations during Forensic investigations. They hold a vital role as a reliable source for a person's unique identification, thus helping law enforcement agencies during criminal investigations. There are three types of prints left by suspects on a crime scene; Visible or patent prints, Plastic prints and Latent fingerprints. Latent or invisible prints have maximum chances of being present at almost every crime scene. Good physical and chemical developmental techniques are required to identify such prints. The variety of these identification methods majorly depends on the type of surfaces on which the fingerprints are found or lifted from. Majority of the previous work has reported effective development of prints on dry surfaces. Such methods include the utilization of various powder techniques [1], Fluorescent powder 
methods [2,3] Silica Gel [4], Iodine fuming on thermal paper [5], multi-metal deposition method [6] etc. The visualization of latent fingerprints submerged on wet surfaces is quite challenging and demands good analytical methods to be developed [7]. In the last couple of years, few researchers in their work have reported the production and usage of Small Particle Reagent technique on wet non-porous surfaces $[8,9,10]$. SPR is a physical development method and is known to be efficient on various surfaces like paper, cardboard, bricks, rocks, concrete, plastic, vinyl, wood, glass and new, rusty or galvanized metal [11]. Dr. GS Sodhi in one of his works (2012), elaborated on the efficiency of Crystal Violet dye in SPR technique [12]. Richa Rohatgi and team in her two publications in 2015 and 2016 mentioned the usage of Crystal Violet and Basic Fuschin dye in SPR method of analysis of Fingerprints from wet non-porous surfaces [13,14]. Theerawat Doibut and his colleague (2016) developed SPR method for Latent fingerprint analysis using Natural dyes like Curcumin and Anthocyanin [15]. Kavleen Kaur et al (2020) prepared a unique SPR formulation using Activated Charcoal and tested it out on Aluminium and Glass Substrates [16]. O.P Jasuja with his colleagues in their work done in 2007 modified the SPR method by replacing detergent with a natural Saponin, an active compound found in a fruit Sapindus mukorossi [17]. Kaneeka Joshi in her research (2015) worked upon developing fingerprints from different substrates like plastic, glass and aluminium, submerged in water for various intervals of time using SPR technique [18].

The aim of this study was to develop a novel SPR formulation using non-toxic as well as cost-effective chemicals. The present work was majorly focussed on finding out the shelf life of such SPR solution prepared for developing the latent fingerprints from non-porous surface.

\section{MATERIALS AND METHODOLOGY}

REQUIREMENTS- Zinc carbonate, Basic Yellow-40 dye, Detergent, UV trans-illuminator, weighing balance etc.

SURFACE OF INTEREST- Aluminium foil

PREPARATION OF SPR SOLUTION- For preparing SPR reagent, $5 \mathrm{~g}$ of Zinc carbonate, 25mg Basic Yellow-40 dye, few drops of any commercial liquid detergent and $75 \mathrm{ml}$ of distilled water were added in a clean beaker and thoroughly mixed. The beaker was then properly covered and was left undisturbed for some time for the solution to saturate.

PROCEDURE- Finger/Thumb print impressions were taken from volunteers on an Aluminium foil surface. Foil was put in a petridish and the prepared SPR reagent was poured on it, until it fully dipped the surface. It was then left undisturbed for 2-3 minutes. After that, the foil was taken out using a forcep and was gently washed under a stream of water for a few seconds. Surface was left to dry under natural room conditions. Developed prints were finally visualized under UV Chamber/Trans illuminator. Photographs of the prints were taken using different colored UV flashlight Torch. The test was performed daily to obtain comprehensive data on the shelf life of the SPR solution prepared.

Table 1 : Scaling for prints

\begin{tabular}{|l|l|l|}
\hline $\begin{array}{c}\text { INTENSITY OF } \\
\text { PRINT }\end{array}$ & SCALE & \multicolumn{1}{|c|}{ QUALITY DESCRIPTION } \\
\hline Identifiable & $8-10$ & $\begin{array}{l}\text { Good quality print; ridges } \\
\text { clear }\end{array}$ \\
\hline & $6-8$ & $\begin{array}{l}\text { Clear ridges with little } \\
\text { background noise and } \\
\text { disturbing contrast }\end{array}$ \\
\hline $\begin{array}{l}\text { Partially } \\
\text { visible }\end{array}$ & $4-6$ & $\begin{array}{l}\text { Smudged partial prints are } \\
\text { visible with much larger } \\
\text { background noise }\end{array}$ \\
\hline
\end{tabular}




\begin{tabular}{|l|l|l|}
\hline $\begin{array}{l}\text { Not } \\
\text { Identifiable }\end{array}$ & $2-4$ & $\begin{array}{l}\text { Very few ridges are visible; } \\
\text { hard to identify the print }\end{array}$ \\
\hline & $0-2$ & $\begin{array}{l}\text { Intense background noise; } \\
\text { Almost full print smudged }\end{array}$ \\
\hline
\end{tabular}

\section{RESULTS AND DISCUSSION}

The Small Particle Reagent technique proved its capability in developing fingerprint marks on a nonporous surface, which was Aluminum foil. The unique feature of this formulation was its fluorescent character because of Basic Yellow dye in the composition. Detergent used proved out to be a good adhesive. Prints developed during the first 10 days by using this method, were accorded a scale of 8-10; being of good quality with clear and identifiable ridges. The prints started developing background noise after 2nd week and were given a scale of 6-7. Between 18-23rd day, prints showed high background noises with lots of smudges and diminished ridge characteristics. After the 25th day, some prints showed extreme smudging and some did not develop at all. The shelf life of the prepared SPR solution was tested out to be 25 days.

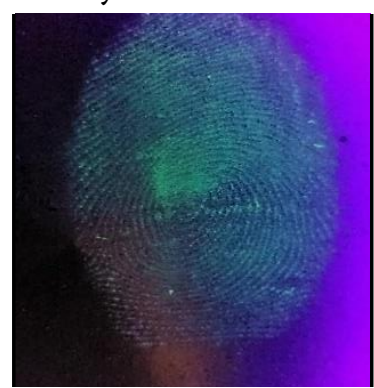

Figure 1: Day 7

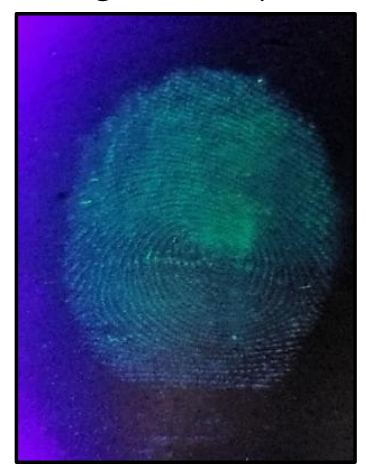

Figure 2: Day 10

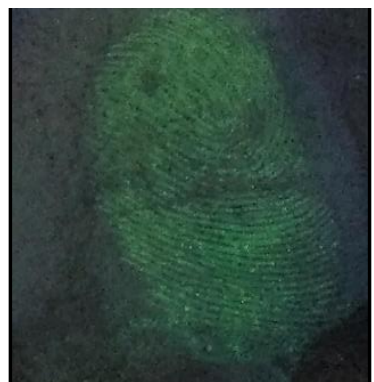

Figure 3: Day 13

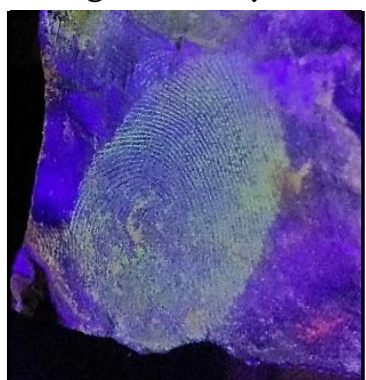

Figure 4: Day 15

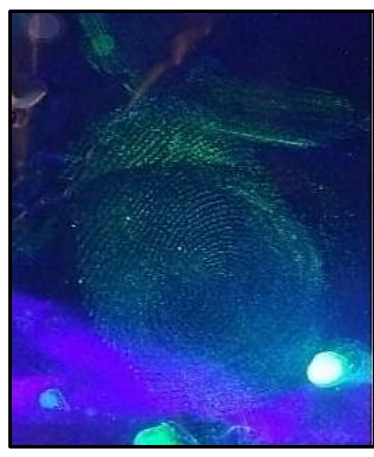

Figure 5: Day 17

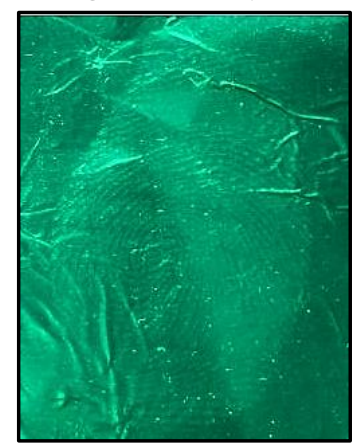

Figure 6: Day 20

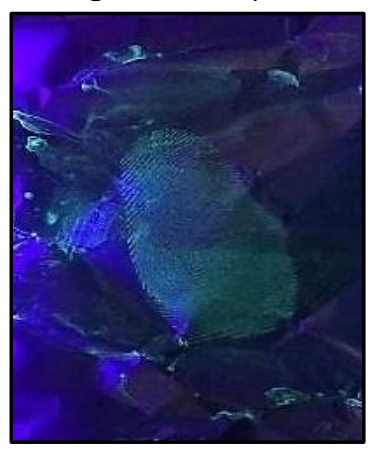

Figure 7: Day 23 


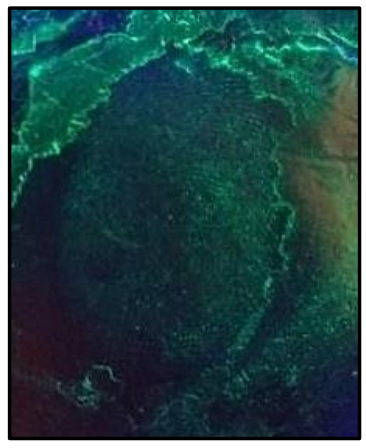

Figure 8: Day 25

\section{IV.CONCLUSION}

Small Particle Reagent Technique is a method for detecting latent fingerprints left on moist or wet surfaces. In the study, we prepared a cost effective novel SPR formulation using Zinc Carbonate and Basic Yellow dye, which showed to be a better substitute over traditional SPR, because of non-toxic and fluorescent contrast. Prints were developed on a wet aluminium surface using the very same solution. The evaluation done on the worth of this formulation was successful and could give clear and clean fingerprint marks once visualized under UV. The lifetime/ Shelf life of the same SPR solution used for the development of all the prints for various days came out to be 25 days, proving the effectiveness and chemical-environmental friendly nature of the formulation.

\section{ACKNOWLEDGEMENT}

The Authors would like to send their gratitude to the faculty and laboratory staff of S.G.T.B. Khalsa College, University of Delhi for their constant guidance throughout the project.

\section{REFERENCES}

[1]. Sodhi GS, Kaur J. Powder method for detecting latent fingerprints: A Review. Forensic Science International 2001; 120(3): 172-176. Available at: https://doi.org/10.1016/s03790738(00)00465-5

[2]. Choi MJ, McBean KE. An evaluation of nanostructured zinc oxide as a fluorescent powder for fingerprint detection. Journal of Materials Science 2008; 43: 732-737. Available at: https://doi.org/10.1007/s10853-007-2178-5

[3]. Wang M, Li M, Yu A, Zhu Y, Yang M, Mao C. Fluorescent Nanomaterials for the Development of Latent Fingerprints in Forensic Sciences. Advanced Functional Materials 2017; 27(14):1606243. Available at: https://doi.org/10.1002/adfm.201606243

[4]. Singh K, Sharma S, Garg RK. Visualization of latent fingerprints using silica gel G. Egyptian Journal of Forensic Sciences 2013; 3(1): 20-25. Available at: https://doi.org/10.1016/j.ejfs.2012.09.001

[5]. Jasuja OP, Singh G. Development of latent finger marks on thermal paper: Preliminary investigation into use of iodine fuming. Forensic Science International 2009; 192(1-3): e11-e16. Available at: https://www.researchgate.net/deref/http\%3A\% 2F\%2Fdx.doi.org\%2F10.1016\%2Fj.forsciint. 200 9.08.005

[6]. Sodhi GS, Kaur J. Multimetal deposition method for detection of latent fingerprints: A Review. Egyptian Journal of Forensic Sciences 2017; 7: 1-7. Available at: https://www.researchgate.net/deref/http\%3A\% 2F\%2Fdx.doi.org\%2F10.1186\%2Fs41935-0170017-7

[7]. Azman AR, Mahat NA, Wahab RA. et al. Relevant visualization technologies for latent fingerprints on wet objects and its challenges: A Review. Egyptian Journal of Forensic Sciences 2019; 9: 1-13. Available at: https://doi.org/10.1186/s41935-019-0129-3

[8]. Kabklang P, Riengrojpitak S, Suwansamrith W. Latent Fingerprint Detection by Various Formulae of SPR on Wet Non-Porous Surfaces. J Sci. Res. Chula. Univ.2009; 34(2): 59-64. Available at: http://www.thaiscience.info/journals/Article/CJ SR/10973025.pdf 
[9]. Cuce P, Polimeni G , Lazzaro AP, Fulvio GD. Small particle reagents technique can help to point out wet latent fingerprints. Forensic Science International 2004; 146: S7-S8. Available at: https://doi.org/10.1016/j.forsciint.2004.09.005

[10]. Madkour S, Sheta A, et al. Development of latent fingerprints on non-porous surfaces recovered from fresh and sea water. Egyptian Journal of Forensic Sciences 2017; 7(1): 1-12. Available at: https://doi.org/10.1186/s41935017-0008-8

[11]. Azman AR, Mahat NA, et al. Novel SafraninTinted Candida rugosa Lipase Nanoconjugates Reagent for Visualizing Latent Fingerprints on Stainless Steel Knives Immersed in a Natural Outdoor Pond. Int. J. Mol. Sci. 2018; 19(6): 1576. Available at: https://doi.org/10.3390/ijms19061576

[12]. Sodhi GS, Kaur J. A novel fluorescent small particle reagent for detecting latent fingerprints on wet non-porous items. Egyptian Journal of Forensic Sciences 2012; 2(2): 45-47. Available at: https://doi.org/10.1016/j.ejfs.2012.04.004

[13]. Rohatgi R, Sodhi GS, Kapoor AK. Small particle reagent based on crystal violet dye for developing latent fingerprints on non-porous wet surfaces. Egyptian Journal of Forensic Sciences 2015; 5(4): 162-165. Available at: https://www.researchgate.net/deref/http\%3A\% 2F\%2Fdx.doi.org\%2F10.1016\%2Fj.ejfs.2014.08. 005

[14]. Rohatgi R, Kapoor AK. Development of latent fingerprints on wet non-porous surfaces with SPR based on basic fuschin dye. Egyptian Journal of Forensic Sciences 2016; 6(2): 179184. Available at: https://doi.org/10.1016/j.ejfs.2015.05.007

[15]. Doibut T, Benchawattananon R. Small particle reagent based on natural dyes for developing latent fingerprints on non-porous wet surfaces. Management and Innovation Technology
International Conference (MITicon) 2016. Available at: https://www.researchgate.net/deref/http\%3A\% 2F\%2Fdx.doi.org\%2F10.1109\%2FMITICON.20 16.8025211

[16]. Kaur K, Sharma T, Kaur R. Development of Submerged Latent Fingerprints on Non-Porous Substrates with Activated Charcoal based Small Particle Reagent. Indian Journal of Forensic Medicine \& Toxicology 2020; 14(3): 388-394. Available at: https://doi.org/10.37506/ijfmt.v14i3.10390

[17]. Jasuja OP, Gagan Deep S, Sodhi GS. Small Particle Reagent: A Saponin-Based Modification. Journal of Forensic Identification 2007; 57: 244-251. Available at: https://www.researchgate.net/publication/2927 49312_Small_particle_reagent_A_saponinbased_modification

[18]. Joshi K, Kesharwani L. Latent fingerprints from non-porous surfaces submerged in water at different interval of time using two SPR formulations. I Journals: International Journal of Software \& Hardware Research in Engineering 2015; 3(9): 15-19. Available at: https://ijournals.in/wpcontent/uploads/2017/07/4.3908-

Kaneeka.compressed.pdf

\section{Cite this article as :}

Akshita Verma, Nisha, Dr. Tulika Banerjee, Dr. G. S. Sodhi, "Development of Latent Fingerprints on NonPorous Surface with Fluorescent Dye Based Small Particle Reagent", International Journal of Scientific Research in Science and Technology (IJSRST), Online ISSN : 2395-602X, Print ISSN : 2395-6011, Volume 8 Issue 3, pp. 443-447, May-June 2021. Available at doi $\quad$ : https://doi.org/10.32628/IJSRST218394 Journal URL : https://ijsrst.com/IJSRST218394 